\title{
ARE YOU READY? Qualifying Social Work Students' Perception of their Preparedness to Work Competently with Service Users from Sexual and Gender Minority Communities
}

\begin{abstract}
Social workers come into contact with lesbian, gay and bisexual (LGB) and trans people in all areas of their practice and across all service user groups. In line with professional requirements, social work educators must ensure that students who complete qualifying programmes successfully meet the standards expected of them as registered social workers, including those around diversity.
\end{abstract}

This study aims to explore the extent to which qualifying social work students feel prepared to practise competently with people from sexual and gender minority communities. Semistructured interviews were conducted with final year social work students at one university in southern England and the results were analysed using thematic analysis.

Whilst these students report feeling generally prepared to practise with sexual minority communities, they report feeling unprepared to practise competently with gender minority communities. Themes that emerged in relation to students' perceived lack of preparedness included unfamiliarity, limited knowledge, fear, and an absence of opportunities to consider relevant issues during their social work training.

Whilst this research relates to a small-scale study at one university, these findings may have broader implications for social work educators in terms of course planning and delivery, particularly around ensuring that students feel ready for practice with all service users.

\section{Keywords}

Trans; Transgender; Lesbian; Gay; Bisexual; Social Work Education 


\section{Introduction}

Across the world, the social work profession is committed to challenging oppression, championing social justice and respecting diversities (IFSW, 2014). The International Association of Schools of Social Work (IASSW) promotes the development of social work education internationally. Principle 4.2 of its statement of ethics affirms that social workers have a responsibility to 'challenge negative discrimination on the basis of [amongst other things] characteristics such as... gender or sex...[and]...sexual orientation...' (IASSW, 2004, p. 2). Within individual countries, social workers and social work educators are bound by national or regional requirements regarding these same principles. For example, in the USA, the Council on Social Work Education's (CSWE) Educational Policy and Accreditation Standards stress the need for social work students to understand the impact of different dimensions of diversity including 'gender identity and expression.... and sexuality' (CSWE, 2008, p. 5). Similarly, in England and Wales, social work education providers must ensure that students who complete their qualifying programmes meet certain standards expected of them as registered social workers, including those around diversity (HCPC, 2014). This understanding must embrace all aspects of human experience and identity including 'sexuality, gender and transgender' (TCSW, 2012, Domain 3). This suggests that, at the point of registration, social workers should be able to practise effectively with service users from sexual and gender minority communities.

In referring to 'sexual and gender minority communities' it is important to note that these are not formed of a single group of people who necessarily share all the same issues and concerns. Sexual minority communities including (although not limited to) lesbians, gay men and bisexuals (LGB) are identified as minorities by virtue of their sexuality. In contrast, other communities are identified as minorities as a result of their gender identity or presentation. Trans is an umbrella term that can be used to refer to this second group of minorities, and encompasses (amongst others) people who identify variously with a gender different to that which they were assigned at birth; a gender that does not conform to social norms; a gender that is outside of the gender binary; or no gender at all.

In social work practice and research, and indeed in the wider world, it is commonplace to see LGB and trans people referred to collectively as 'LGBT'. However, the relationship between the communities referred to under this acronym has sometimes been uneasy (Fish, 2012; Richardson \& Monro, 2012), with both LGB and trans people feeling that their concerns 
differ significantly. The label can run the risks of conflating identities and needs in a misleading way, and can lead to the neglect of important issues (Fredriksen-Goldsen et al, 2011). In particular, the concerns of bisexual and trans people are often 'marginalized...within the LGBT acronym' (Richardson \& Monro, 2012, p. 43).

There is increased recognition that every person's experience of being LGB or trans is different and mitigated by the intersection of other social characteristics such as social class or race (Crenshaw, 1991). However, there are commonalities in the way that sexual and gender minorities experience oppression (Worthen, 2013), particularly in terms of the interlinked nature of homophobia, transphobia and sexism. There is a "seepage of "sexuality" and "gender" as discrete categories' (Richardson \& Monro, 2012, p. 43), illustrated by the way in which both gender and sexual boundaries are policed by dominant masculinities and sexualities. An example of this is the use of terms such as 'sissy' to discipline men who are perceived as not conforming to dominant masculine norms, whether they identify as gay or trans or indeed neither (Richardson \& Monro, 2012; Rottneck, 1999). In response to this, LGB and trans groups are increasingly coming together, for example in the case of Stonewall in the UK, to campaign for equality (Hunt \& Manji, 2015).

\section{Context}

Social workers come into contact with LGB and trans people in all areas of their practice and across all service user groups but consistent and reliable information about these communities as users of social work services is relatively uncommon due to a reluctance on the part of many public bodies to monitor the sexual orientation and gender identity of their service users (Fish, 2012). However, given that much research indicates trans people are exposed to an increased risk of becoming homeless, developing problematic drug and alcohol use, receiving a psychiatric diagnosis, experiencing domestic abuse (Whittle et al, 2007) or becoming socially isolated (e.g. Siverskog, 2014) compared to the wider population, it is inevitable that social workers will be called upon to support members of these communities in addition to working with them as potential adopters, foster carers and colleagues.

However, despite this, and in apparent contradiction to the need to meet the professional requirements described above, LGB and trans issues do not feature highly in the social work curriculum. Research from North America into social work lecturers' feelings about the 
inclusion of LGB and trans teaching in the curriculum (Fredriksen-Goldsen et al, 2011; Woodford et al, 2013), appears to indicate that, whilst there is broad support for the inclusion of content on LGB issues, there is less support for the inclusion of teaching about trans people or transphobia. A survey of social work program directors and faculty members in the USA (Martin et al, 2009) also found that issues around gender identity and expression are covered less well in the curricula than those around LGB issues. In the United Kingdom, a Stonewall study of health and social care workers (which included social workers), found that nearly three-quarters of participants reported having no LGBT content in their training, and less than a quarter reported having had any training on working with trans service users (Somerville, 2015).

In terms of preparation for practice, a recent online survey of 1,018 American and Canadian LGBTQ (lesbian, gay, bisexual, transgender and queer) social work students (Craig et al, 2016) found low levels of self-assessed readiness to practise with specific subpopulations, particularly trans populations. In addition, the findings of a recent survey undertaken on behalf of Stonewall in the UK (Somerville, 2015), suggest that more than one in ten workers in health and social care settings (including social workers) do not feel confident in their ability to understand or meet the needs of LGB people, and that a quarter of them are not confident in their ability to respond to the specific care needs of trans people. These findings are somewhat supported by evidence provided to the United Kingdom House of Commons Women and Equalities Committee (House of Commons Women \& Equalities Committee, 2016) by Mermaids UK, a charity supporting families and children around gender identity issues, who claimed that social workers '....appear to act on their own prejudices rather than researching gender issues' (House of Commons Women \& Equalities Committee, 2016, p. 77). The Committee concluded that there was 'worrying evidence' (House of Commons Women \& Equalities Committee, 2016, p. 78) about some social workers' lack of knowledge in relation to trans issues, and a lack of appropriate training of social care staff on this topic.

The small-scale, qualitative study to be described in this paper set out to explore further into students' perceived preparedness (or otherwise) to work with service users from sexual and gender minorities, and to examine some of the reasons behind this.

\section{Research Question}


Do qualifying social work students feel prepared by their social work training to work competently with service users from sexual and gender minority communities?

\section{Methods}

Researcher:

A single researcher was involved in the design of this study, and in the collection and analysis of the data. This researcher is employed as a senior lecturer within the social work department in which the research was conducted Some of the implications of this are discussed below under 'Ethical Considerations' and 'Limitations'. The researcher was supervised throughout by her research mentor (a senior member of academic staff and experienced researcher).

This researcher identifies as lesbian and is open about her minority sexuality status. Although the researcher identifies as cisgender (i.e. not trans), she has a particular interest in gender identity which provided the motivation to carry out this study, and has a gender-subverting, butch lesbian gender expression. Again, issues relating to this are discussed in the 'Limitations' section below.

\section{Participants}

All 37 final year (undergraduate and postgraduate) social work students at one university in southern England were invited by email to take part in the study. In total, 10 students $(27 \%$ of the potential total) volunteered to take part. Two students were following the undergraduate programme, and eight were following the postgraduate programme. Although not directly asked, during the course of the interviews four students disclosed that they belonged to a sexual minority community themselves. No one disclosed membership of a gender minority community.

\section{Interviews}

Individual semi-structured interviews, containing a combination of both pre-planned and unplanned questions (Carey, 2013), were conducted with each participant. These lasted around 30 minutes and were audio recorded using a digital recorder. 
Participants were asked to talk about how prepared or otherwise they felt to work competently with both LGB and trans service users. They were asked to compare their levels of preparedness to work with both groups, and prompted to identify any concerns they might have. Participants were also asked to consider any teaching they may have had, either in the classroom or whilst on practice placement, about LGB and trans issues, and encouraged to make any suggestions about teaching that they felt were appropriate.

\section{Analysis}

Each interview was transcribed in full and then analysed using the Framework Method of thematic analysis (Ritchie \& Lewis, 2003). Thematic analysis is the most commonly employed approach to data analysis in social work empirical research (Carey, 2013), and is a method of 'identifying, analysing and reporting patterns (themes) within data' (Braun \& Clarke, 2006, p. 79). It involves the researcher familiarising herself with the data, generating initial codes, and then identifying and clarifying 'themes', which are elements from the data of significance to the research question. The Framework Method provides a consistent way of ordering the data according to both theme and interview in order to facilitate this analysis.

Thematic analysis is not a 'passive' (Braun \& Clarke, 2006, pp. 79, 80) process - the researcher plays an active role in identifying, highlighting and drawing out relevant themes. The particular significance of the identity of the researcher analysing the data is explored below under 'Limitations'.

\section{Ethical Considerations}

The fact that the researcher who carried out this study is employed as a lecturer within the social work department in which the research was conducted demands that important ethical issues around 'the power relationship between the researcher and researched' (Farrimond, 2013, p. 4) are addressed. When conducting research on students, particular attention must be paid to obtaining informed consent, and ensuring confidentiality (Cleary et al, 2014).

\section{Informed consent}

Although students may be in all other ways capable of making informed decisions, they are in a dependent relationship with faculty undertaking research, and thus rendered vulnerable to coercion, or the perception of coercion, in some of the same ways as patients who participate 
in medical research (Leentjens \& Levenson, 2013). Consequently, researchers have a 'duty of care' (Leentjens \& Levenson, 2013, p. 397) towards their participants. In this study, informed consent was delivered primarily through the use of a comprehensive Participant Information Sheet and Consent Form. These documents explained the purpose and nature of the research; emphasised the voluntary nature of involvement in the study and the right of participants to withdraw at any time; highlighted the potential risks and benefits of involvement; and provided the contact details of an independent person, outside of the students' course team, who could be contacted for queries or complaints. Potential participants were sent this information in a private email prior to their agreeing to participation in the study.

\section{Confidentiality}

Students were recruited to the study via private emails. The names of those participating were not shared with anyone other than the researcher. The recordings and transcriptions of the interviews were anonymized, and participants were reassured that information would not be shared with anyone other than the researcher and her supervisor. However, it was also highlighted that there were limits to this confidentiality. For example, if a participant had mentioned anything that raised concerns about their own or someone else's practice, particularly in terms of posing a risk to children or vulnerable adults, the researcher, a registered social worker herself, would have been obliged to break confidentiality, which could ultimately have impacted on the participant's progress on the course. The Participant Information Sheet and Consent Form clearly outlined the limits of this confidentiality.

It was on this basis that ethical approval was obtained from the relevant university Research Ethics Committee.

\section{Findings}

The findings can be divided into three main areas:

1. Students' perceived readiness to practise competently with LGB and trans populations.

2. Teaching on LGB and trans issues during social work training.

3. Students' suggestions for future teaching on trans issues. 
1. Students' Perceived Readiness to Practise Competently with LGB and Trans Populations

(i) LGB service users

'I would feel completely competent with gay, lesbian and bisexual [service users]...' (Interview 7)

All students in this study reported feeling prepared to work competently with LGB service users. Levels of confidence varied a little between individuals, but all interviewees mentioned feeling 'confident', 'fairly confident', 'very competent', 'competent', 'quite competent' or 'fairly competent'.

However, participants did not attribute this feeling of preparedness to anything they had been taught on the course, with one student (who had described herself as feeling 'very competent') commenting,

'I don't think the course has prepared me at all.' (Interview 7)

In fact, the emergent theme in relation to feelings of preparedness was that of familiarity or 'normality'. Participants attributed this familiarity or 'normality' to a number of factors:

Own sexuality - Four students mentioned their own minority sexuality identity as influential in preparing them for practice with LGB service users.

Friends, flat-mates \& family members' sexuality - Four students mentioned that they had close friends or family who identified as LGB and said that this had enabled them to gain some insight into issues facing minority sexuality communities that could be applied to their work with service users.

Previous work or placement experience - Eight students said they had worked with LGB service users and/or colleagues on their practice placements or in previous jobs and that these experiences had prepared them for future work with sexual minority communities. For example,

'I've worked with lots of...gay people, straight people, bisexual people, lesbians, whatever, before...I'm used to that, it's like normal.' (Interview 3) 
Location - Five students felt that the city in which they lived and studied had an influence on their preparedness to work with service users from sexual minority communities. The city has a reputation for being accepting of diversity and there are a relatively high proportion of LGBT people living there (BHCC, 2014). Some students believed this contributed to their feelings of familiarity, 'normality' and, ultimately, preparedness.

The concepts of familiarity and 'normality' and their relevance to this area of practice will be further explored in the discussion below.

(ii) Trans service users

'I don't feel prepared...' (Interview 4)

All students in this study expressed concern about their preparedness to work competently with service users from trans communities, although levels of concern varied a little amongst individuals. Those who expressed the least concern attributed this to same 'familiarity factors' identified above. For example, one student stated:

'I feel like I'm more prepared than most people, having trans friends...' (Interview 5)

However, this student later acknowledged,

'I don't feel like anyone can feel completely confident. I think especially with trans women, I haven't really known that many trans women, it's mostly been trans men.' (Interview 5)

A strong emergent theme in relation to lack of preparedness to work competently with trans service users was that of lack of knowledge. For example,

'I don't know a great deal about transgender...maybe I've watched a couple of things on telly...' (Interview 9)

Some also felt they lacked knowledge about the particular issues facing trans service users, how to approach potentially sensitive topics with trans people, the legal status of trans people, and how their agency might expect them to work with trans people.

Another strong emergent theme in relation to lack of preparedness was that of fear. For example, 


\section{'If you said to me now: "Your next visit is to [a trans service user]"...I would probably go into a panic.' (Interview 9)}

Three students expressed fear that they would cause offence to trans service users. Three students felt they might use the 'wrong' language when talking to or about trans service users. Three students were also fearful of causing an embarrassing situation. For one student this embarrassment was linked directly to their lack of knowledge in that they worried they would become embarrassed when their ignorance was exposed.

(iii) Comparing levels of preparedness to work with LGB and trans service users

'I think out of all the areas that is the area I feel I know less about.' (Interview 4)

Students were asked to compare how prepared they felt to work with LGB service users with how prepared they felt to work with trans service users. All students said they felt less prepared to practise competently with trans service users than they felt to work with LGB service users. This highlights the importance of ensuring the perspectives and needs of service users from all communities are adequately addressed in both research and teaching in order to avoid the needs of some minorities being subsumed beneath those of others. An example of the way this can happen occurred when one student originally assumed that she had been asked about her preparedness to work with 'LGBT' service users and had answered that she felt 'quite confident' (Interview 4). However, when asked later in the interview specifically about her preparedness to work with trans service users she responded:

'Actually, can I retract... what I said earlier? I don't feel so prepared, not as prepared. I think it's an area where I know less about the issues, and have less comprehension of the issues, than...issues to do with sexuality.' (Interview 4)

When comparing levels of preparedness the issues of familiarity and normality arose again with one student saying:

'I have friends who are gay and bisexual. It's more normal...[than being trans]' (Interview 1)

Although this student acknowledged that 'normal' was 'perhaps not the best word to use', it continued to arise throughout this interview and others. 


\section{Teaching on LGB and Trans Issues During Social Work Training}

(i) Teaching on LGB issues

'It's just we never spoke about lesbian, gay, bisexual, whatever.' (Interview 9)

Most students felt there was no classroom teaching, or not enough classroom teaching, on LGB issues during their social work training. Students who could remember teaching that addressed LGB issues spoke of only two things: a film drama about older lesbians, and a case study in which the main protagonists were gay men.

A strong emergent theme was that of students experiencing a clear separation between 'classroom' learning and 'placement' learning, illustrated by the following quote:

'I actually had some training on diversity at...[placement]...last year... and I found it fascinating...But they don't cover anything like that on the course...' (Interview 1)

As mentioned above, eight students at least partly attributed their preparedness to practice with LGB service users to the fact that they had worked with them previously, often on placement. It is apparent that many students do not think about what they learn on placement as part of their social work course in the same way as what they learn in the classroom.

(ii) Teaching on trans issues

\section{'Well there's zero. Zero. Which is madness really.' (Interview 7)}

No students could recall any classroom teaching about trans issues during their social work training. However, three students had worked with trans people during their practice placements and two of these students had had training on trans issues within the placement agency. However, one student was clear that this training was not routinely offered to social work staff and had only been arranged at the students' request.

When discussing the lack of trans teaching on the course, a strong emergent theme was that of there already being 'too much' to fit into the course teaching. Seven students mentioned 
this, six of whom were following the postgraduate study route, a course that is one year shorter than the undergraduate route. For example,

'...in terms of trans, I don't want to say "you're too small a group to be concerned with", but I'm also conscious of just the sheer amount you try to shoehorn into the eighteen months that you're actually studying.' (Interview 10)

Despite these concerns, another strong emergent theme was the need for social work courses to be covering trans issues. For example,

'...identity is so huge to the work that we do...' (Interview 9) and,

'...we need...to have frontline social workers knowing that stuff and making a bit of a pathway and being a bit of a voice and we're not preparing people for that.' (Interview

Some students felt this need might be higher if they were preparing to work with certain service user groups (although some felt the need for training in trans issues would be more important in adult services, whereas others felt it would be more important when working with children). Some also felt the need for training on these issues might vary according to geographical location. However, there was no consensus on which areas would benefit from more training with two students saying it would be more important in a city with a high proportion of trans people, and two others saying it would be more important in rural areas where trans people may be very isolated and deprived of services.

\section{Students' Suggestions for Future Teaching on Trans Issues}

All students interviewed had suggestions about how teaching on trans issues could be included in their social work course with most students suggesting one or more of the following:

Case studies - Two students suggested that the inclusion of trans service users in case studies would be useful in terms of encouraging and facilitating learning about the issues. For example,

'I...find working with case studies really, really relevant...[and]... a good way of working in groups and actually thinking about what all the issues are.' (Interview 4) 
Student discussion and debate - Four students said they would like more opportunities to discuss and debate issues around working with trans people. They felt this was important in terms of 'rehearsing' the correct language to use, and correcting any misunderstandings. For example,

'...in the classroom being able to challenge each other's prejudices...being able to talk about things in certain environments is always useful. Learning how to express yourself because it's where you need to be 'called out' if you say anything that is insensitive, rather than with any service users...' (Interview 2)

Linked to this need for more classroom discussion a theme of lack of confidence in fellow students' competence in terms of working with diversity emerged, with five students spontaneously mentioning this. For example,

'There's people that I would worry about a little bit on the course. They're lacking. But it's not their fault.' (Interview 7) and,

'I find it strange that I have reached this point and...I still don't know what their attitudes are or what their knowledge is like.' (Interview 2)

These students felt that facilitated discussion would be an effective way in which students could learn more themselves and develop more confidence in their peers' abilities.

Service user involvement - The most popular suggestion for incorporating trans issues into teaching (with seven of these students suggesting it) was for trans service users to directly contribute to the teaching. For example,

'I think there should be much more work meeting people from these different groups, even if they make up a small percentage.' (Interview 7) and,

'One of the things this course has done very well is involving service users and actually having people come in and say what their experiences are like...' (Interview 10)

There was an acknowledgement amongst some of these students that not all trans people would want to share their experiences with social work students, but there remained a wish for this to happen. 
Methods of including trans issues in the social work curriculum will be explored further in the discussion below.

\section{Limitations}

There are, of course, limitations to this study. It is a small-scale, exploratory study conducted at just one university in southern England. The city in which the research took place has an unusually high proportion of residents who identify as LGB - possibly as many as 11-15\% (BHCC, 2014) compared to the estimated national average of $1.6 \%$ (ONS, 2014) - and is known to have a significant trans community (Hill \& Condon, 2015), estimated at twice the national average (Reed et al, 2009). The potential significance of this will be explored further in the discussion below.

In addition, this was a self-selecting cohort in that all the students who took part volunteered for the study, and some had a particular interest in sexual and gender minority communities, either through their previous work experience or their own personal circumstances. Both undergraduate and postgraduate students took part in the study, but these courses are different, particularly in terms of the amount of classroom teaching provided. The students were asked about their perception of their own preparedness but this may not, of course, reflect the extent to which they are actually prepared, or otherwise, to practise with service users from sexual and gender minority communities. Some may have over-estimated their preparedness, some may have underestimated it (Craig, 2016).

Furthermore, as discussed above, the researcher is a senior lecturer in the social work department in which the research was conducted. Although not familiar with all the students who took part, the impact of this in terms of power could have influenced some responses. Unless student participants in research are reassured of the non-coercive nature of a study, some may provide answers they assume the researcher wants (Cleary et al, 2014). The safeguards discussed above under 'Ethical Considerations' should have mitigated against this.

Finally, as previously discussed, the researcher openly identifies as lesbian and has a butch lesbian gender expression. This is not uncommon - it is probable that most research into issues around sexual minorities is carried out by people who identify as lesbian or gay (Alexander, 2003) - and it does not necessarily undermine the findings of this study. 
However, it could have impacted the research in two main ways. Firstly, the sexuality of the researcher may have impacted upon the collection of the data. The researcher arguably occupied an 'insider' position (Hayfield \& Huxley, 2015, 91) in terms of the focus of the research and at least four of the participants (who identified as members of sexual minority communities). This insider status has the potential to confer a familiarity with the area of study, and an ability to respond more competently to issues raised in semi-structured interviews (Perry, Thurston \& Green, 2004). However, it can also potentially cause researchers to fail to pursue certain lines of inquiry, or to allow follow-up questioning to be led by an 'emotional, rather than intellectual' (Perry, Thurston \& Green, 2004, p. 143) response to what is being said. Participants' knowledge of the researcher's minority sexuality and gender expression may also have caused some of them to regulate their comments, perhaps in order to avoid saying anything they thought might offend the researcher or harm her feelings. Secondly, the sexuality of the researcher may have impacted on the analysis of the data. When using thematic analysis to manage data collected using semi-structured interviews 'the researcher is inevitably bound up with the process' (Perry, Thurston \& Green, 2004, p. 143). The themes that emerge from any data do not simply pre-exist within it. Indeed, "if themes "reside" anywhere, they reside in our heads from our thinking about our data and creating links as we understand them' (Ely et al, 1997, pp. 205-6). An insider status can sometimes assist in the forming of these links by creating a deeper understanding of the realities contained in the data. However, it can also potentially distort understandings as a result of an over-familiarisation with certain narratives and experiences (Perry, Thurston \& Green, 2004).

Although the researcher occupied an insider position in relation to some aspects of the research, this was not true for all aspects. In particular, she does not identify as trans. When conducting research of this kind, it is important to be aware of this nuanced and intersectional nature of identity (Crenshaw, 1991). An alertness to all these limitations formed part of the critical and reflexive approach the researcher took in relation to this study.

\section{Discussion}

The discussion that follows will be structured around the same three areas highlighted in the results section. 
1. Students' perceived readiness to practise competently with LGB and trans populations.

Previous studies in North America and the UK (Craig et al, 2016; Somerville, 2015) have found that social work students and social care practitioners report lower levels of preparedness to work competently with certain communities under the LGBT umbrella than others. In particular, people report less confidence in their abilities to work with service users from trans communities. These findings were broadly echoed in this current study in which all students expressed at least some level of concern about their ability to work effectively with trans service users. However, the same previous studies (Craig et al, 2016; Somerville, 2015) identified that some social work students and social care professionals also lack confidence in their ability to meet the needs of LGB service users. This was not evident in this current study.

The students themselves attributed much of their confidence in working with LGB service users to feelings of familiarity. As described above, they attributed this familiarity to factors such as their own sexual orientation, the relatively high numbers of LGB people in the city in which they were studying, and their personal acquaintance with LGB individuals. Attitudes held about certain groups of people do not always correlate with levels of competence to work with them (Logie, Bridge \& Bridge, 2007). However, attitudes are a vital part of developing culturally competent social work practice with LGB and trans service users (Van Den Bergh \& Crisp, 2004). Some social work students may 'harbour lingering vestiges of prejudice, with or without their conscious knowledge' (Salzburg, 2015), so this is an area worth paying some consideration to.

There is much evidence that attitudes towards LGB people are greatly affected by proximity and acquaintance (Berkman \& Zinberg, 1997; Black et al, 1999). For example, contact with lesbians and gay men, both socially and as service users, has been found to correlate with lower levels of homophobia (Weiner, 1989 cited in Black et al, 1999), and having lesbian or gay acquaintances, friends or family members has been found to be related to lower levels of homophobia and higher standards of anticipated professional behaviour amongst social work students (Cramer, Oles \& Black, 1997). Williams (1997) stresses the importance of personal contact with LGB people in affecting attitudes by stating that one-to-one personal contact 'is 
more effective than all the parades, protest marches, political lobbying, and educational lectures put together' (7).

The trans population is higher in the city in which the students in this study were studying than in other parts of the UK (however, at an estimated 1.2\%, or 2,760 individuals (Hill \& Condon, 2015), it is significantly smaller than the LGB population). Trans Pride marches are becoming increasingly common worldwide (McConnell, 2014) and, despite ongoing prejudice, trans people are becoming more visible in all areas of life including politics (Trevett, 2014; Aitkenhead, 2015), sport (Halliday, 2014; Lutz, 2015), entertainment (Gjorgievska \& Rothman, 2014), and academia (Whittle, 2007; Halberstam, 1998). Furthermore, trans people are no longer only visible as social work service users - they are also increasingly visible as foster carers (Williams \& Andalo, 2015) and social workers themselves (Mott, 2013). However, the familiarity with trans communities felt by the students in this study was clearly not equivalent to the familiarity they spoke of feeling with LGB communities.

Another aspect worthy of discussion, and one that is linked to familiarity, is the way in which some students in this study used the word 'normal' to describe people from LGB communities - a word they did not employ when discussing members of trans communities. During the past two or three decades, much discourse around LGB equality has involved an emphasis on 'normalcy', as opposed to the 'abnormal or unnatural' way in which members of LGB communities were previously perceived (Richardson, 2004). For example, recent campaigns have centred on aspects such as equal marriage and parenting rights, or equality within the armed forces, with much attention focussed on the way that LGB people are just the same as heterosexual people. Although the students who used the word 'normal' implied that they found it somewhat unsatisfactory or inappropriate to describe people in this way (for example, by apologising or using 'air quotation marks'), they did not replace it with alternatives, indicating perhaps that they have embraced this powerful discourse. However, Richardson (2004) warns that the 'consequences of "gay normalization" may be uneven' (p.400), in that only certain kinds of identities and behaviours will be considered normal. As such, the 'normal gay' (Richardson, 2004, p. 397) is one who embraces marriage-like family values, displays national pride, and is 'gender conventional' (Seidman, 2002, p. 133). As a result, new concepts of otherness will arise around those who exist outside of these norms (Richardson, 2004), for example many trans people, regardless of their sexuality. This could be of particular significance here. 
Another factor that students identified as contributing to their perceived lack of preparedness to work with trans service users, was a lack of knowledge. This lack of knowledge, or 'trans competence' (Siverskog, 2014, p. 397) is something that service users themselves have commented on. Siverskog's Swedish life story interviews with older trans people found that service users regularly experienced social workers' lack of knowledge on trans issues, and sometimes felt the need to educate the social workers themselves - a situation they found highly unsatisfactory. The need for education of social workers in issues of importance to trans communities will be returned to below.

2. Teaching on LGB and trans issues during social work training.

Students in this study could recall very little teaching input on LGB issues, and none at all on trans issues. These findings echo those of Craig et al (2016) who found that North American social work students reported relatively low levels of LGBTQ-specific curriculum content, with less than a third reporting lesbian and gay content, and substantially fewer reporting content relating specifically to bisexual or trans people. A US survey of social work program directors and faculty (Martin et al, 2009) revealed fairly widespread inclusion of LGB content in the curriculum. However, the authors identified a need for more, particularly around LGBT youth and trans people.

A North American online survey of social work faculty (Fredriksen-Goldsen et al, 2011) found that whilst $94 \%$ of the US respondents and $98 \%$ of the Canadian respondents indicated that curriculum content about LGB people was important or very important, $18 \%$ of the US sample and $9 \%$ of the Canadian sample indicated that content about trans people was less than important. Faculty support for inclusion of curriculum content on transphobia was even lower with $38 \%$ of US and $28 \%$ of the Canadian respondents indicating it is less than important.

There is a danger that, unless care is taken to include specific teaching around trans issues, this can get subsumed (and most likely neglected) by a (potentially uninformed) staff team and student body who believe that 'LGBT issues' have been addressed when, in fact, only LGB issues have. Trans people have been largely neglected in social work research and practice (Fish, 2012). This research, and other studies identified here, indicate they are also 
being overlooked in social work education, and leadership is urgently required, from policy makers and faculty, to ensure this changes (Leyva, 2015).

It may not be the content of the taught curriculum or placement experiences alone that contribute to the education of social work students in terms of their perceived preparedness to practise with gender minorities (Martin et al, 2009). Other factors, such as institution and program-level support for students from these communities, admissions materials that represent and promote diverse communities, openly LGBTQ faculty, the use of rainbow stickers and safe space signs, and teaching staff who possess knowledge about these issues both in the university and on placement (Craig et al, 2016; Martin et al, 2009; Messinger, 2002) have been suggested as of great importance in affecting students' feelings of preparedness for practice.

Given the social work's espoused values and the professional requirements outlined above it is essential that consideration is given as to how to include more teaching on trans issues in the curriculum. In the UK, the House of Commons Women \& Equalities Committee have recommended that formal training for social workers must be addressed 'as a matter of urgency' (2016, p. 78). Students in this study were very clear about their desire for trans issues to be included as part of their social work training, and even suggested some ideas of how this could be done.

3. Students' suggestions for future teaching on trans issues.

Students in this study suggested three ways in which trans issues could be included on the social work curriculum: case studies, student discussions, and service user involvement.

Case studies: Most of the students who remembered teaching on LGB issues being included in their course recalled working with a case study or watching a film drama, and two of them identified case studies as learning opportunities they found helpful and would like to repeat. It has been suggested (Bassett \& Day, 2003) that these kinds of teaching tools can be effective in developing attitudes of acceptance and empathy, particularly in social work students whose opinions and attitudes around sexual and gender minorities are not yet fullyformed. This is especially effective if, rather than being used as a one-off event or confined to 
a single module, these are 'infused' throughout the curriculum, thus nurturing empathic responses and prompting cognitive dissonance within students who may hold judgemental attitudes (Bassett \& Day, 2003).

Student discussions: A number of students mentioned that they would have welcomed the opportunity to engage in more structured discussions and debates with their peers around working with trans people as a way of rehearsing some of the issues and provoking reflection. Opportunities to critically reflect are essential in order to allow students to fully question the assumptions on which non-culturally competent practice with trans people is based. For example, social work students would benefit from space wherein they could reflect on their own gender identity, their personal responses to the gender identity of others, and the gender binary with its links to the oppression of trans people (Hartley \& Whittle, 2003; Burdge, 2007; Markman, 2011). Salzburg (2015) advocates a way of teaching and learning in which social work educators facilitate this kind of reflection by 'posing questions that allow room for students to subvert familiar storylines that underlie assumptions' (p. 214).

Students also mentioned that group discussions might allow them to understand more about the attitudes of their fellow students. This doubting of one's peers echoes the findings of Craig et al's study in which the surveyed LGBTQ students identified their non-LGBTQ colleagues as having significantly lower levels of readiness to practise than themselves. More discussions may increase levels of group confidence and preparedness.

Service user involvement - The teaching intervention that most students identified as potentially useful in learning about trans issues was to have trans people themselves contribute directly to the teaching. As the earlier discussion around familiarity indicated, there is some evidence that meeting and knowing people from minority groups could impact positively on attitudes and readiness to practice. McClintock (1992) reports on the benefit for students of attending presentations or panel discussions with LGB people, in that hearing them speak about their real life experiences, and entering into dialogue with panellists allows participants to replace whispered stereotypes with complex human reality...[it]...is in itself a profound emotional and intellectual experience' (p. 54). 
Following the study described in this current paper, a teaching session, delivered by a local LGBT youth agency, was arranged for this student cohort. This was co-facilitated by a trans user of the service. Immediate informal student feedback was very positive, with many people commenting that this was the first trans person they had knowingly met. Research (Black et al, 1999) conducted around LGB service users suggests that the impact of a one-off event such as this may be limited, and that ongoing content on minority issues across the curriculum may be more effective. It would be interesting to conduct further research into the impact this session had on students' levels of perceived preparedness to work effectively with trans people, but this is beyond the scope of this study.

\section{Conclusion}

Trans people are becoming increasingly visible across many areas of society, and referrals to Gender Identity Clinics are growing by an average of 25-30\% each year (House of Commons Women \& Equalities Committee, 2016). However, there remains compelling evidence that transphobia continues to negatively impact the lives of trans people in critical ways. For example, recent research suggests that nearly half of young trans people have attempted suicide at least once (Nodin et al, 2015), with many reporting transphobic bullying as a contributory factor.

Historically, the social work profession has been at the frontline of challenging this kind of oppression and advocating on behalf of persecuted minorities (Morrow, 1993). Writing about gay and lesbian adolescents in 1993, social work academic, Deanna Morrow, made the point that 'no oppressed group has ever been granted dignity, respect and human rights by remaining silent,' (Morrow, 1993, p. 658), and called for social workers to come forward to 'dispel negative stereotypes, myths and discrimination aimed at lesbian and gay individuals' (Morrow, 1993, p. 659). Nearly quarter of a century on, social work education has the potential to play a vital role in equipping new social workers with the knowledge, skills and confidence to recognise and challenge oppression, and to respond effectively to the needs of trans people.

Although a number of participants in this study highlighted concerns about the amount of topics they have to cover during their social work training, there was broad consensus about 
the need to include teaching on trans issues, and a recognition of the centrality of a critical understanding of identity and gender across all areas of social work. Without teaching in this area, students remain potentially unprepared to practice competently with a growing and increasingly visible trans population. Furthermore, if it does nothing to improve inclusion of trans issues within the curriculum and wider faculty processes, social work education could be neglecting the needs of future social workers who identify as trans by potentially failing to provide a welcoming and inclusive academic environment.

Social workers are 'ethically obligated and uniquely situated to become educated about and work to eliminate issues of oppression faced by the transgender and gender-nonconforming communities' (Markman, 2011, p. 316). The fact that students may be qualifying and registering as social workers whilst not feeling confident of their ability to practice competently with service users from trans communities is a serious issue for social work educators, as it could be in contravention of the profession's own international and national requirements (IASSW, 2004; TCSW, 2012; HCPC, 2014). The House of Commons Women and Equalities Committee report (2016), with its unequivocal recommendation that training on trans issues for social workers be urgently addressed, is a timely reminder of the urgent need to bridge this gap between stated aims and practice. Most importantly, it is the service users from these diverse communities who stand to benefit from a more informed and confident workforce who are fully prepared to assist with the real job of social work, that of challenging oppression and championing social justice. 


\section{References}

Aitkenhead, D. (2015) Emily Brothers: Labour's First Transgender Candidate: I Walked Into the Sea. Something Brought Me Back.' The Guardian. 3 January 2015. Retrieved from: http://www.theguardian.com/society/2015/jan/03/emily-brothers-labours-first-transgendercandidate-interview

Alexander, C.J. (2003) When the researcher is gay or lesbian Journal of Gay and Lesbian Social Services 14(4): 105-108

Bassett, J.D. \& Day, K.J. (2003) A test of the infusion method Journal of Teaching Social Work 23(3-4): 29-41

Berkman, C.S. \& Zinberg, G. (1997) Homophobia \& heterosexism in social workers Social Work 42(4): 319-332

Black, B., Oles, T.P., Cramer, E.P. \& Bennett, C.K. (1999) Attitudes \& behaviors of social work students toward lesbian \& gay male clients Journal of Gay \& Lesbian Social Services 9(4): 47-68

Braun, V. \& Clarke, V. (2006) Using thematic analysis in psychology. Qualitative Research in Psychology 3(2): 77-101

BHCC Brighton \& Hove City Council - Corporate Policy \& Research Team (2014) Brighton \& Hove City Snapshot: Report of Statistics 2014 Brighton \& Hove: Brighton \& Hove City Council

Burdge, B. (2007) Bending gender, ending gender: Theoretical foundations for social work practice with the transgender community Social Work 52(3): 243-250

Carey, M. (2013) The Social Work Dissertation: Using Small-Scale Qualitative Methodology ( $2^{\text {nd }}$ ed) Maidenhead: McGraw Hill

Cleary, M., Walter, G. \& Jackson, D. (2014) Above all, 'do no harm': Key considerations when including students as research participants in higher education settings Contemporary Nurse 49: 93-95 
CSWE Council on Social Work Education. (2008) Educational Policy and Accreditation Standards. Retrieved from http://www.cswe.org/File.aspx?id=41861

Craig, S.L., Dentato, M.P., Messinger, L. \& McInroy, L.B. (2016) Educational determinants of readiness to practise with LGBTQ clients: Social work students speak out British Journal of Social Work 46: 115-134

Cramer, E.P., Oles, T. \& Black, B. (1997) Reducing social work students' homophobia: An evaluation of teaching strategies Arete 21(2): 36-49

Crenshaw, K.W. (1991) Intersectionality and identity politics: Learning from violence against women of colour in M. Stanley \& V Naryan (eds) Restructuring Feminist Political Theory: Feminist Perspectives (pp. 178-193) Cambridge: Polity Press

Ely, M., Vinz, R., Downing, M. \& Anzul, M. (1997) On Writing Qualitative Research: Living By Words London: Falmer

Farrimond, H. (2013) Doing Ethical Research Basingstoke: Palgrave Macmillan

Fish, J. (2012) Social Work and Lesbian, Gay, Bisexual and Trans People Bristol: Policy Press

Fredriksen-Goldsen, K.I., Woodford, M.R., Luke, K.P. \& Gutierrez, L. (2011) Support of sexual orientation and gender identity content in social work education: Results from national surveys of US and Anglophone Canadian faculty Journal of Social Work Education 47(1), 19-35.

Gjorgievska, A. \& Rothman, L. (2014) Laverne Cox is the First Transgender Person Nominated for an Emmy - She Explains Why That Matters. Time Magazine. 10 July 2014. Retrieved from: http://time.com/2973497/laverne-cox-emmy/

Halberstam, J. (1998) Female Masculinity. Durham \& London: Duke University Press

Halliday, J. (2014) Boxing Legend Frank Maloney Reveals New Life as a Woman. The Guardian. 10 August 2014. Retrieved from: http://www.theguardian.com/sport/2014/aug/10/kellie-maloney-boxing-transgender 
Hartley, C. \& Whittle, S. (2003) Differently sexed and gendered bodies demand different ways of thinking about policy and practice Practice 15(3): 61-73

Hayfield, N. \& Huxley, C. (2015) Insider and outsider perspectives: Reflections on researcher identities in research with lesbian and bisexual women Qualitative Research in Psychology 12(2): 91-106

HCPC Health and Care Professions Council. (2014). Standards of Education and Training. London: HCPC

Hill, A. \& Condon, R. (2015) Brighton \& Hove Trans Needs Assessment Brighton: Brighton \& Hove City Council

House of Commons Women \& Equalities Committee (2016) Transgender Equality: First Report of the Session 2015-16 London: The Stationery Office

Hunt, R. \& Manji, A. (2015) Trans People and Stonewall: Campaigning together for lesbian, gay, bisexual and trans equality London: Stonewall

IASSW International Association of Schools of Social Work (2004) Ethics in Social Work: Statement of Principles Retrieved from http://www.iassw-aiets.org/ethics-in-social-workstatement-of-principles/

IFSW International Federation of Social Workers (2014). Global Definition of the Social Work Profession. Retrieved from http://ifsw.org/policies/definition-of-social-work/

Leentjens, A.F.G. \& Levenson, J.L. (2013) Ethical issues concerning the recruitment of university students as research subjects Journal of Psychosomatic Research 75: 394-398

Leyva, V.L. (2015) Mental health inequalities among LGBT older people in the United States: curricula developments in J. Fish \& K. Karban (eds) (2015) Lesbian, Gay \& Bisexual Health Inequalities: International Perspectives in Social Work (pp. 237-252) Bristol: Policy Press

Logie, C., Bridge, T.J. \& Bridge, P.D. (2007) Evaluating the phobias, attitudes, and cultural competence of Master of Social Work students toward the LGBT populations Journal of Homosexuality 53(4): 201-221 
Lutz, T. (2015) Caitlyn Jenner Accepts Courage Award: 'If You Want to Call Me Names, I Can Take It'. The Guardian. 16 July 2015 Retrieved from: http://www.theguardian.com/sport/2015/jul/15/caitlyn-jenner-receives-espy-award-and-saystransgender-people-deserve-respect

Markman, E. (2011) Gender Identity Disorder: the gender binary, and transgender oppression: Implications for ethical social work Smith College Studies in Social Work 81(4): 314-327

Martin, J.I., Messinger, L., Kull, R., Holmes, J., Bermudez, F. \& Sommer, S. (2009) Sexual Orientation and Gender Expression in Social Work Education: Results from a National Survey Dulles, VA: Council on Social Work Education

Messinger, L. (2002) Policy \& practice: A holistic approach to addressing homophobia and heterosexism among social work students Journal of Lesbian Studies 3(3-4): 121-132

McClintock, M. (1992) Sharing lesbian, gay and bisexual life experiences face to face Journal of Experiential Education 15(3): 51-55

McConnell, F. (2014) Trans Pride Brighton. The Guardian. 29 July 2014 Retrieved from: http://www.theguardian.com/world/2014/jul/29/trans-pride-brighton-share-your-pictures-andvideos

Morrow, D. (1993) Social work with gay and lesbian adolescents Social Work 38(6): 655-660

Mott, S. (2013) Choosing social work as a transgender career. Huffpost Gay Voices. 30 December 2013. Retrieved from: http://www.huffingtonpost.com/stephanie-mott/choosingsocial-work-as-a_b_4512844.html

Nodin, N., Peel, E., Tyler, A. \& Rivers, I. (2015) The RaRE Research Report: LGB\&T Mental Health - Risk and Resilience Explained London: PACE (Project for Advocacy Counselling and Education)

ONS Office for National Statistics (2014) Integrated Household Survey Retrieved from: http://webarchive.nationalarchives.gov.uk/20160105160709/http://www.ons.gov.uk/ons/rel/in tegrated-household-survey/integrated-household-survey/january-to-december-2013/sty-factsabout-lgb-community-in-the-uk.html 
Perry, C., Thurston, M. \& Green, K. (2004) Involvement and detachment in researching sexuality: reflections on the process of semi-structured interviewing Qualitative Health Research 14(1): 135-148

Reed, B., Rhodes, S., Schofield, P., Wylie, K. (2009) Gender Variance in the UK: Prevalence, Incidence, Growth and Geographic Distribution. Ashtead: GIRES

Richardson, D. (2004) Locating sexualities: from here to normality Sexualities 7(4): 391-411

Richardson, D. \& Monro, S. (2012) Sexuality, Equality and Diversity Basingstoke: Palgrave Macmillan

Ritchie, J. \& Lewis, J. (2003) Qualitative Research Practice London: Sage

Rottneck, M. (ed.) (1999) Sissies and Tomboys - Gender nonconformity and homosexual childhood New York: New York University

Salzburg, S, (2015) Pedagogy for unpacking heterosexist and cisgender bias in social work education in the United States in J. Fish \& K. Karban (eds) (2015) Lesbian, Gay \& Bisexual Health Inequalities: International Perspectives in Social Work (pp. 205-222) Bristol: Policy Press

Seidman, S. (2002) Beyond the Closet: The Transformation of Gay and Lesbian Life New York: Routledge

Siverskog, A. (2014) 'They just don't have a clue': Transgender aging and implications for social work Journal of Gerontological Social Work 57:2-4, 386-406

Somerville, C. (2015) Unhealthy Attitudes: The treatment of LGBT people within health and social care services London: Stonewall. Retrieved from http://www.stonewall.org.uk/what_we_do/research/11388.asp

TCSW The College of Social Work. (2012). Professional Capabilities Framework. London: TCSW. Retrieved from: https://www.basw.co.uk/pcf/

Trevett, C. (2014) Georgina Beyer Joins Mana Party. The New Zealand Herald. 27 July 2014. Retrieved from: http://www.nzherald.co.nz/nz/news/article.cfm?c_id=1\&objectid=11299918 
Van Den Bergh, N. \& Crisp, C. (2004) Defining culturally competent practice with sexual minorities: implications for social work education \& practice Journal of Social Work Education 40(2): 221-238

Weiner, A.P. (1989) Racist, sexist, and homophobic attitudes amongst social work students and the effects on their assessments of client vignettes Unpublished Doctoral Dissertation, New Brunswick, NJ: Rutgers University

Whittle, S., Turner, L. \& Al-Amani, M. (2007) Engendered Penalties: Transgender and Transsexual People's Experiences of Inequality and Discrimination London: Press for Change

Williams, W.L. (1997) Introduction in J.T. Sears \& W.L. Williams (eds) Overcoming Heterosexism \& Homophobia: Strategies that Work (pp. 1-9) New York, NY: Columbia University Press

Williams, R. \& Andalo, D. (2015) Gay, bisexual and transgender foster parents and adopters step forward. The Guardian. 4 March 2015 Retrieved from: http://www.theguardian.com/social-care-network/2015/mar/04/gay-bisexual-transgenderfoster-parents-adopters

Woodford, M.R., Brennan, D.J., Gutierrez, L. \& Luke, K.P. (2013) US social work faculty's attitudes toward lesbian, gay, bisexual and transgender people. Journal of Social Service Research 39, 50-62. doi: 10.1080/01488376.2012.666936

Worthen, M.G. (2013) An argument for separate analyses of attitudes toward lesbian, gay, bisexual men, bisexual women, MtF and FtM transgender individuals Sex Roles 68, 703-723 